\title{
BMJ Open Spectrum of COVID-19 clinical characteristics among patients presenting to the primary healthcare in Qatar during the early stages of the pandemic: a retrospective multicentre cross-sectional study
}

\author{
Mansoura Ismail, ${ }^{1,2}$ Anwar Joudeh (D) ,3,4 Ayman Al-Dahshan (D) , \\ Muna Mehdar Alsaadi, ${ }^{1}$ Samya Al Abdulla, ${ }^{6}$ Nagah Abdel Aziz Selim ${ }^{7,8}$
}

To cite: Ismail M, Joudeh A, AlDahshan $A$, et al. Spectrum of COVID-19 clinical characteristics among patients presenting to the primary healthcare in Qatar during the early stages of the pandemic: a retrospective multicentre crosssectional study. BMJ Open 2021;11:e051999. doi:10.1136/ bmjopen-2021-051999

- Prepublication history and additional supplemental material for this paper are available online. To view these files, please visit the journal online (http://dx.doi.org/10.1136/ bmjopen-2021-051999).

Received 02 April 2021 Accepted 05 November 2021

Check for updates

(c) Author(s) (or their employer(s)) 2021. Re-use permitted under CC BY-NC. No commercial re-use. See rights and permissions. Published by BMJ.

For numbered affiliations see end of article.

Correspondence to

Dr Anwar Joudeh;

anwarjoudeh@gmail.com

\section{ABSTRACT}

Objectives To describe clinical characteristics and laboratory investigations of patients with COVID-19 diagnosed in primary care in Qatar and to assess predictors of hospitalisation.

Design A retrospective cross-sectional study.

Setting and participants 3515 confirmed patients with COVID-19 diagnosed in any of the 27 primary healthcare centres in Qatar between 9 April 2020 and 30 June 2020. Main outcome measures Demographic characteristics, comorbidities, contact tracing, clinical and laboratory data, in addition to patient disposition at the time of diagnosis Results Mean age of patients was 35.5 years $( \pm 14.7)$. 2285 patients $(65.0 \%)$ were males, 961 patients $(27.3 \%)$ had a history of concomitant comorbidity and 640 patients (18.2\%) were asymptomatic. Adult patients (19-64 years old) were more likely to report symptoms than children or elderly. Fever and cough were the most frequently documented symptoms affecting 1874 patients (46.7\%) and 1318 patients $(37.5 \%)$, respectively. Most patients had normal vital signs at presentation; however, patients who were subsequently hospitalised had higher median temperature than non-hospitalised patients $\left(37.7^{\circ} \mathrm{C}\right.$, IQR: $37.0^{\circ} \mathrm{C}-38.4^{\circ} \mathrm{C}$, and $37.2^{\circ} \mathrm{C}$, IQR: $36.8^{\circ} \mathrm{C}-37.8^{\circ} \mathrm{C}$, respectively). Hospitalised patients had significantly higher C reactive protein (CRP) (median CRP: $20 \mathrm{mg} / \mathrm{L}$, IQR: 5.0-61.2 $\mathrm{mg} / \mathrm{L}$ ) than non-hospitalised patients (median CRP: $4.6 \mathrm{mg} / \mathrm{L}$, IQR: $1.7-11.50 \mathrm{mg} / \mathrm{L}$ ), and lower median absolute lymphocyte count $\left(1.5 \times 10^{3} / \mu \mathrm{L}\right.$, IQR: $1.1 \times 10^{3} / \mu \mathrm{L}-$ $2.1 \times 10^{3} / \mu \mathrm{L}$, and $1.8 \times 10^{3} / \mu \mathrm{L}$, IQR: $1.3 \times 10^{3} / \mu \mathrm{L}-2.4 \times 10^{3} /$ $\mu \mathrm{L}$, respectively). Predictors of hospitalisation were increasing age (adjusted OR (AOR): 2.614, 95\% Cl 1.281 to 5.332 for age between 50 years and 64 years, and AOR: $3.892,95 \% \mathrm{Cl} 1.646$ to 9.204 for age $\geq 65$ years), presence of two or more comorbidities (AOR: 2.628; 95\% $\mathrm{Cl} 1.802$ to 3.832) and presence of symptoms (AOR: 1.982: $95 \% \mathrm{Cl} 1.342$ to 2.928 ).

Conclusion The majority of COVID-19 cases diagnosed in primary healthcare in Qatar were symptomatic. Most cases had normal vital signs and laboratory results at presentation. Predictors of hospitalisation were increasing
Strengths and limitations of this study

- This study reflects primary healthcare experience on clinical characteristics and laboratory findings of confirmed COVID-19 cases.

- Patients were included from all health centres distributed in Qatar reflecting different socioeconomic backgrounds.

- Data were extracted from electronic medical records which were incomplete for some patients.

- Likely, patients with severe illness presented directly to secondary care.

age, the presence of symptoms and having two or more comorbidities

\section{INTRODUCTION}

Since the emergence of COVID-19 in Wuhan, China, in December 2019, enormous pressure has been exerted on the healthcare systems to cope with the rising number of cases alongside maintaining their essential functionalities. During this pandemic, primary healthcare continued to be the primary point of contact for patients with COVID-19 and non-COVID19-related conditions. ${ }^{1}$ Given the non-specific features of this infectious disease, even more pressure is placed on primary care physicians in making decisions on which suspected or confirmed patients with COVID-19 to send home, refer to specialists or send to hospital. ${ }^{2}$

The WHO defined confirmed cases of COVID-19 as persons with laboratory confirmation of COVID-19 who could either be asymptomatic or symptomatic. Symptomatic cases are further classified into mild, moderate, severe or critically ill. ${ }^{3}$ Transmission 
mainly occurs from symptomatic or pre-symptomatic infected people to others by close contact through respiratory droplets, with an average incubation period of 5-6 days, although it might extend up to 14 days. ${ }^{4}$

According to Lipsitch et al, expansion of the public health service is necessary to elucidate the epidemiology of this novel virus and to characterise its potential impact. More studies are needed to define the impact of the COVID-19 pandemic by measuring the number of persons infected, the infection's transmissibility and the spectrum of clinical severity. Counting the number of cases in the whole spectrum of disease severity, ranging from asymptomatic patients to different degrees of symptomatology to death, will better calibrate the epidemic spread of this infection. ${ }^{5}$ Also, understanding the clinical characteristics of COVID-19 and predictors of hospitalisation is essential information for primary healthcare physicians who are the first point of contact to the community, especially that around $80 \%$ of patients with COVID-19 have a mild disease. ${ }^{6}$

\section{Role of PHCC in Qatar during the early stages of the pandemic} and patient flow

In Qatar, Primary Health Care Corporation (PHCC) is considered the main provider of primary healthcare to both citizens and expatriates through 27 health centres distributed all over the country. In 2019, 1.4 million out of the 2.8 million total population in Qatar were registered with one of the PHCC health centres. ${ }^{7}$ The first reported case in Qatar was in February 2020 for a Qatari male who returned from Iran. In March 2020, Qatar started reporting increased numbers of COVID-19 positive cases where national restrictions were put in place. In responding to the outbreak of COVID-19, the Ministry of Public Health in Qatar developed an emergency action plan with the collaboration of both primary and secondary care institutions represented by PHCC and Hamad Medical Corporation, respectively. ${ }^{7}$

In addition to testing patients who fit the criteria for COVID-19, PHCC contributed to a large scale of community screening by conducting contact tracing of confirmed cases, testing patients at the country's ports of entry, as well as screening community members who were known to have comorbidities and or were older than 55 years of age. $^{8}$

In response to the pandemic, PHCC introduced several changes to its service, including dedicating 4 out of the 27 health centres as test and hold facilities, while rearranging triaging areas in the rest health centres to separate suspected cases of COVID-19 from other patients and provided at least one room for COVID-19 testing. Once patients were identified to have confirmed COVID-19 disease, further investigations were done, including laboratory tests (full blood count, renal function test, liver function test and $\mathrm{C}$ reactive protein (CRP)), chest X-ray and ECG. Patients' disposition to quarantine facilities or referral to hospital was dependent on their disease severity classification categorised in alliance with the
National Institute of Health guidelines ${ }^{9}$ (online supplemental table 1) were patients who were asymptomatic or had mild disease were sent to quarantine, whereas patients with moderate, severe or critical illness were referred to hospital. However, the decision of hospitalisation was made by secondary care physicians.

An earlier epidemiological study by Al Kuwari et al on the first 5685 cases of confirmed COVID-19 cases in Qatar during the period of 28 February-18 April 2020 found that the vast majority of the patients were young males with few comorbidities and were mostly asymptomatic. ${ }^{10}$ However, less information is available on patients with COVID-19 who presented to the primary care in the subsequent period of the earlier study where the infection had spread from the young male working group to the rest of the community affecting older people and those with comorbidities. It is also important to identify characteristics of patients with asymptomatic infections and predictors of hospitalisation among patients presenting to the primary healthcare. Identifying these features will help to map the disease burden and guide the pandemic management at the primary healthcare level.

Therefore, this study aimed to describe clinical characteristics and laboratory investigations of patients with COVID-19 diagnosed at the primary care in Qatar during the period of 9 April-30 June 2020, and to assess characteristics of asymptomatic infections and predictors of hospitalisation among those patients.

\section{MATERIALS AND METHODS}

\section{Study design and setting}

This was a multicentre, retrospective cross-sectional study. Research data were extracted by the health information management department in PHCC on patients with positive COVID-19 reverse transcriptase-PCR (RT-PCR) who were diagnosed in any of the 27 health centres across the country during the period of 9 April-30 June 2020. All patients who had their CDC notification forms completed on Cerner electronic medical records (Cerner EMR) were included in the study (a total of 3515 patients).

\section{Data collection and study variables}

The following data were extracted from Cerner EMR using a unique medical record number for each patient: (1) demographic information such as age, gender, nationality and occupation, (2) comorbidities, including (a) diabetes mellitus, (b) hypertension, (c) asthma, (d) cardiovascular diseases, including ischaemic heart disease, heart failure, arrhythmia and stroke, (e) chronic kidney disease, (f) cancer, (g) immunodeficiency disorders and $(\mathrm{h})$ chronic lung disease, including chronic obstructive pulmonary disease, interstitial lung disease and bronchiectasis, (3) symptoms of COVID-19, (4) vital signs (5) laboratory results, (6) contact tracing and (7) patients' disposition at the time of diagnosis of COVID-19. Comorbidities were extracted using the International Classification of Diseases 10th edition, Australian Modification. Symptoms 
of COVID-19 were collected from a built-in CDC notification form that was prompted whenever a pre-approved diagnosis code for COVID-19 was entered into Cerner. A confirmed case of COVID-19 was defined as a positive result on real-time RT-PCR assay of nasal and oropharyngeal swab specimens. ${ }^{11}$ Nasopharyngeal and throat swabs were collected from suspected cases with symptoms suggesting COVID-19 and from close contacts of confirmed COVID-19 cases. Close contacts were defined based on the US Centers for Disease Control and Prevention criteria as 'any individual who was within 6 feet of an infected person for at least 15 min starting from 2 days before illness onset or, if asymptomatic, 2 days before positive specimen collection'. ${ }^{12}$ Also, PHCC contributed to screening travellers at the country's port of entry as well as individuals older than 55 years of age and/or those with comorbidities. All biological samples were sealed and transferred to the laboratory in strict accordance with the standard protocol. Real-time RT-PCR was used to detect SARS-CoV-2 infections using TaqPath COVID-19 Combo Kit (Thermo Fisher Scientific, Waltham, Massachusetts, USA) or Cobas SARS-CoV-2 test (Roche Diagnostics, Rotkreuz, Switzerland). These tests are highly sensitive and specific with no cross-reactivity against multiple other respiratory viruses. ${ }^{12-14}$

\section{Statistical analysis}

The data were analysed using the IBM SPSS Statistics for Windows (version 23, IBM Corp., Armonk, N.Y., USA). Both descriptive and analytic statistics were applied. For the descriptive statistics, frequency distribution tables and percentages were used for categorical variables while mean and SD were used for numeric variables when data were normal or as medians and IQRs otherwise. For analytical statistics, Student's t-test and Mann-Whitney $\mathrm{U}$ test was applied for numerical outcomes, while the $\chi^{2}$ test was applied for categorical outcomes. Multivariable logistic regression analysis was performed to identify the predictors of hospital admission. Statistical significance was considered at $\mathrm{p}<0.05$.

\section{Patient or public involvement}

Patients or the public were not involved in the design, or conduct, or reporting, or dissemination plans of our research

\section{RESULTS}

We extracted and analysed demographic data, clinical characteristics, and laboratory investigations for 3515 patients with confirmed COVID-19, who were diagnosed in 27 primary healthcare centres across Qatar during the period of ninth of April to 30th of June 2020. Table 1 shows the demographic characteristics of COVID-19 cases in primary care. Most cases were in the age group 19-49 and the mean age was 35.5 $( \pm 14.7)$. About two-thirds of the cases $(65.0 \% ; n=2285)$ were males. The most frequent nationality was Indian
Table 1 Demographic characteristics of COVID-19 cases in primary care in Qatar, $2020(\mathrm{~N}=3515)$

\begin{tabular}{lc}
\hline Variable & Frequency (\%) \\
\hline Age (years) & \\
\hline 18 & $423(12.0)$ \\
\hline $19-49$ & $2518(71.6)$ \\
\hline $50-64$ & $480(13.7)$ \\
\hline$\geq 65$ & $94(2.7)$ \\
\hline Mean \pm SD & $35.5 \pm 14.7$ \\
\hline Gender & \\
\hline Female & $1230(35.0)$ \\
\hline Male & $2285(65.0)$ \\
\hline Nationality & \\
\hline Indian & $783(22.3)$ \\
\hline Qatari & $541(15.4)$ \\
\hline Egyptian & $427(12.1)$ \\
\hline Pakistani & $374(10.6)$ \\
\hline Bangladeshi & $249(7.1)$ \\
\hline Filipino & $235(6.7)$ \\
\hline Sudanese & $137(3.9)$ \\
\hline Others* & $774(21.9)$ \\
\hline Arab & $1523(43.3)$ \\
\hline Non-Arab & $1992(56.7)$ \\
\hline Occupation & \\
\hline Unemployed & $382(14.3)$ \\
\hline Service workers & $662(24.7)$ \\
\hline Office staff & $591(22.1)$ \\
\hline Technical professional & $286(10.7)$ \\
\hline Students & $188(7.0)$ \\
\hline Healthcare professionals & $88(3.3)$ \\
\hline Housewife & $226(8.4)$ \\
\hline Others & $252(9.4)$ \\
\hline Ming data & \\
\hline
\end{tabular}

Missing data: occupation $(n=840)$.

*Includes Lebanese, Kenyan, Tunisian, Ethiopian, Saudi, Somali, Indonesian, Jordanian, Nepalese, Iranian, Syrian, Sri Lankan, Palestinian and Yemeni.

(22.3\%; $\mathrm{n}=783)$, followed by Qatari $(15.4 \% ; \mathrm{n}=541)$, Egyptian (12.1\%; $\mathrm{n}=427)$, and Pakistani (10.6\%; $\mathrm{n}=374)$. A quarter of patients $(24.7 \% ; \mathrm{n}=662)$ were service workers and $22.1 \%(n=591)$ were office staff.

Table 2 displays the distribution of comorbidities of COVID-19 cases. About three-quarters of patients $(72.7 \% ; \mathrm{n}=2554)$ had no known comorbidity. Of those who had any comorbidity $(27.3 \%$; $\mathrm{n}=961)$, about $64 \%$ $(\mathrm{n}=618)$ had one comorbidity and almost a quarter $(24.3 \% ; \mathrm{n}=234)$ had two comorbidities. Frequent comorbidities among infected persons included diabetes mellitus $(14.8 \% ; \mathrm{n}=520)$, hypertension $(13.2 \% ; n=465)$, asthma $(8.3 \% ; n=292)$, and cardiac disease $(2.5 \% ; \mathrm{n}=87)$. 


\begin{tabular}{|c|c|}
\hline Variable & Frequency (\%) \\
\hline \multicolumn{2}{|l|}{ Presence of any comorbidities } \\
\hline Yes & $961(27.3)$ \\
\hline No & $2554(72.7)$ \\
\hline \multicolumn{2}{|c|}{ Number of comorbidities $(\mathrm{n}=961)$} \\
\hline One & $618(64.3)$ \\
\hline Two & $234(24.3)$ \\
\hline Three or more & $109(11.3)$ \\
\hline Diabetes mellitus & $520(14.8)$ \\
\hline Hypertension & $465(13.2)$ \\
\hline Asthma & $292(8.3)$ \\
\hline Cardiac disease & $87(2.5)$ \\
\hline Chronic kidney disease & $44(1.3)$ \\
\hline Cancer/immunodeficiency & $25(0.7)$ \\
\hline Chronic lung disease* & $9(0.3)$ \\
\hline
\end{tabular}

*Includes chronic lung diseases other than asthma: chronic obstructive pulmonary disease, interstitial lung disease and bronchiectasis.

Almost one-third of patients with COVID-19 (33.1\%; $\mathrm{n}=1163$ ) reported a history of contact with suspected or confirmed COVID-19 cases. As shown in table 3, most patients with COVID-19 (81.8\%; n=2875) reported having COVID-19-related symptoms while the remaining cases $(18.2 \% ; \mathrm{n}=640)$ reported no symptoms. Of those who had symptoms, about $40 \%(\mathrm{n}=1157)$ reported one symptom, $35.5 \% \quad(\mathrm{n}=1022)$ reported two symptoms and about a quarter $(24.2 \% ; \mathrm{n}=696)$ reported three or

Table 3 Frequency of reported symptoms of COVID-19 cases in primary health settings in Qatar $(\mathrm{N}=3515)$

\begin{tabular}{lc}
\hline Variable & Frequency (\%) \\
\hline $\begin{array}{l}\text { Presence of symptoms } \\
\text { Yes }\end{array}$ & $2875(81.8)$ \\
\hline No & $640(18.2)$ \\
Number of symptoms (n=2875) & \\
$\quad$ One & $1157(40.2)$ \\
$\quad$ Two & $1022(35.5)$ \\
\hline Three or more & $696(24.2)$ \\
Fever & $1874(46.7)$ \\
Cough & $1318(37.5)$ \\
\hline Sore throat & $1112(31.6)$ \\
Headache & $497(14.1)$ \\
Runny nose & $345(9.8)$ \\
Shortness of breath/dyspnoea & $197(5.6)$ \\
Myalgia/arthralgia & $102(2.9)$ \\
Diarrhoea & $73(2.1)$ \\
\hline
\end{tabular}

more symptoms. Fever was the most frequently reported symptom $(46.7 \% ; \mathrm{n}=1874)$ followed by cough $(37.5 \%$; $\mathrm{n}=1318)$, sore throat $(31.6 \% ; \mathrm{n}=1112)$, headache $(14.1 \%$; $\mathrm{n}=497)$ and runny nose $(9.8 \% ; \mathrm{n}=345)$.

On diagnosis of COVID-19, the majority of patients $(87 \% ; n=2913)$ were placed in quarantine/isolation facilities and the remaining cases were hospitalised (13\%; $\mathrm{n}=433)$.

Table 4 describes the relationship between the patients' background characteristics and the presence of symptoms. On bivariate analyses, adult patients (19-64 years old) were more likely to report symptoms compared with children or elderly patients. Furthermore, non-Arabs were more likely to have symptoms compared with Arabs (83.5\% vs $79.6 \%, \mathrm{p}=0.003)$. Also, hospitalised patients were significantly more likely to have symptoms compared with their counterpart group.

Table 5 displays the vital signs and laboratory results of patients with COVID-19 according to the treatment setting. Most patients had normal vital signs readings at presentation, although the mean respiratory rate (RR) and heart rate (HR) were at the upper limits of normal (mean RR 19.5 \pm 2.2 SD, mean HR 94.0 \pm 15.5 SD). In addition, hospitalised patients had a higher median temperature than non-hospitalised patients $\left(37.7^{\circ} \mathrm{C}\right.$, IQR: $37.0^{\circ} \mathrm{C}-38.4^{\circ} \mathrm{C}$, and $37.2^{\circ} \mathrm{C}$, IQR: $36.8^{\circ} \mathrm{C}-37.8^{\circ} \mathrm{C}$, respectively) (table 5).

Regarding laboratory results, most patients had normal full blood count and renal and liver function tests. However, the median value for neutrophils count $\left(2.9 \times 10^{3} / \mu \mathrm{L}\right.$ vs $\left.2.6 \times 10^{3} / \mu \mathrm{L}\right)$, alanine aminotransferase $(31.7 \mathrm{U} / \mathrm{L}$ vs 27.0 $\mathrm{U} / \mathrm{L})$ and aspartate aminotransferase $(35.0 \mathrm{U} / \mathrm{L}$ vs 27.6 $\mathrm{U} / \mathrm{L}$ ) was higher in the hospitalised group. In addition, some laboratory results differed significantly between the two groups; the median absolute lymphocyte count in hospitalised patients was lower than in non-hospitalised patients $\left(1.5 \times 10^{3} / \mu \mathrm{L}\right.$, IQR: $1.1 \times 10^{3} / \mu \mathrm{L}-2.1 \times 10^{3} / \mu \mathrm{L}$, and $1.8 \times 10^{3} / \mu \mathrm{L}$, IQR: $1.3 \times 10^{3} / \mu \mathrm{L}-2.4 \times 10^{3} / \mu \mathrm{L}$, respectively). Also, hospitalised patients had a significantly higher CRP value (median CRP: $20 \mathrm{mg} / \mathrm{L}$, IQR: $5.0-61.2 \mathrm{mg} / \mathrm{L}$ ) than non-hospitalised patients (median CRP: $4.6 \mathrm{mg} / \mathrm{L}$, IQR: $1.7-11.50 \mathrm{mg} / \mathrm{L}$ ) (table 5).

Table 6 describes the relationship between the patients' background characteristics and the treatment setting. On bivariate analyses, increasing age was significantly associated with hospital admission. Also, males were more likely to be hospitalised than females $(14.1 \%$ vs $10.8 \%$, $\mathrm{p}=0.008$ ). Moreover, hospitalisation was higher among patients who had a higher number of comorbidities. As well, symptomatic patients were more likely to be hospitalised than asymptomatic patients $(14.1 \%$ vs $7.9 \%$, $\mathrm{p}<0.001)$.

All factors tested in the bivariate analysis were included in the logistic regression analysis. Adjusted OR (AOR) and the $95 \%$ CI for predictors of hospital admission are presented in table 7 . Patients aged 50-64 years and $\geq 65$ years were 2.6 times and 3.9 times more likely to be hospitalised than those who were aged 18 years or less, 
Table 4 Relationship between the characteristics of COVID-19 cases and the presence of symptoms (N=3515)

\begin{tabular}{|c|c|c|c|}
\hline Variable & Symptomatic, n (\%) & Asymptomatic, n (\%) & $P$ value \\
\hline Age (years) & & & $<0.001^{*}$ \\
\hline$\leq 18$ & $309(73.0)$ & $114(27.0)$ & \\
\hline $50-64$ & $403(84.0)$ & $77(16.0)$ & \\
\hline$\geq 65$ & $73(77.7)$ & $21(22.3)$ & \\
\hline Female & 995 (80.9) & $235(19.1)$ & \\
\hline Male & $1880(82.3)$ & $405(17.7)$ & \\
\hline Nationality & & & $0.003^{*}$ \\
\hline Arab & $1212(79.6)$ & $311(20.4)$ & \\
\hline Non-Arab & $1663(83.5)$ & $329(16.5)$ & \\
\hline Office staff & $507(85.8)$ & $84(14.2)$ & \\
\hline Technical professional & $249(87.1)$ & $37(12.9)$ & \\
\hline Students & $140(74.5)$ & $48(25.5)$ & \\
\hline Healthcare professionals & $69(78.4)$ & $19(21.6)$ & \\
\hline Housewife & $195(86.3)$ & $31(13.7)$ & \\
\hline Unemployed & $314(82.2)$ & $68(17.8)$ & \\
\hline Others & $207(82.1)$ & $45(17.9)$ & \\
\hline The presence of any comorbidities & & & 0.558 \\
\hline No & $2083(81.6)$ & $471(18.4)$ & \\
\hline
\end{tabular}

*Statistically significant.

respectively. Also, hospital admission was higher among patients who had two or more comorbidities (AOR: 2.62; 95\% CI 1.80 to 3.83 ) compared with patients who had no chronic health condition. Also, patients who had symptoms were about two times more likely to be hospitalised compared with patients who had no symptoms (AOR: 1.98; $95 \%$ CI 1.34 to 2.92 ).

\section{DISCUSSION}

This is a retrospective cross-sectional study that described the clinical characteristics and laboratory investigations of 3515 patients with confirmed COVID-19 who were diagnosed in the primary care in Qatar during the early stages of the pandemic. The majority of patients were males with a median age of 35.5 years, and most of them were symptomatic but with normal vital signs and laboratory investigations. Increasing age, the presence of symptoms and having two or more comorbidities were predictors of hospitalisation.

\section{Baseline characteristics of patients with COVID-19}

The mean age of confirmed patients with COVID-19 who were diagnosed in PHCC during the study period was comparable to the mean age for diagnosed patients with COVID-19 in a national study in Kingdom of Saudi Arabia (KSA) (36 years) during the early stages of the pandemic ${ }^{15}$ and lower than the median age of 47 years in China ${ }^{16}$ and Kuwait. ${ }^{17}$ In the current study, males represented $(65 \%)$ of the total studied population which is a higher percentage than that reported in similar studies in KSA and China (54.3\% and $58.1 \%$, respectively) and comparable to the study in Kuwait $(63 \%) .{ }^{15-17}$ This might reflect the unique demographic structure of Qatar, where $88 \%$ of the population are expatriate workforce and around three-quarters of them are males with a current median age of 33 years. ${ }^{18}$ The rate of comorbidities reported in this study $(27.3 \%)$ was also similar to what was reported in KSA and China (20.1\% and $23.7 \%$, respectively). ${ }^{15} 16$

In contrast, an earlier epidemiological study by Al Kuwari et al on COVID-19 spread in Qatar from 28 February 2020 
Table 5 Vital signs and laboratory results of COVID-19 cases according to the treatment setting $(\mathrm{N}=3515)$

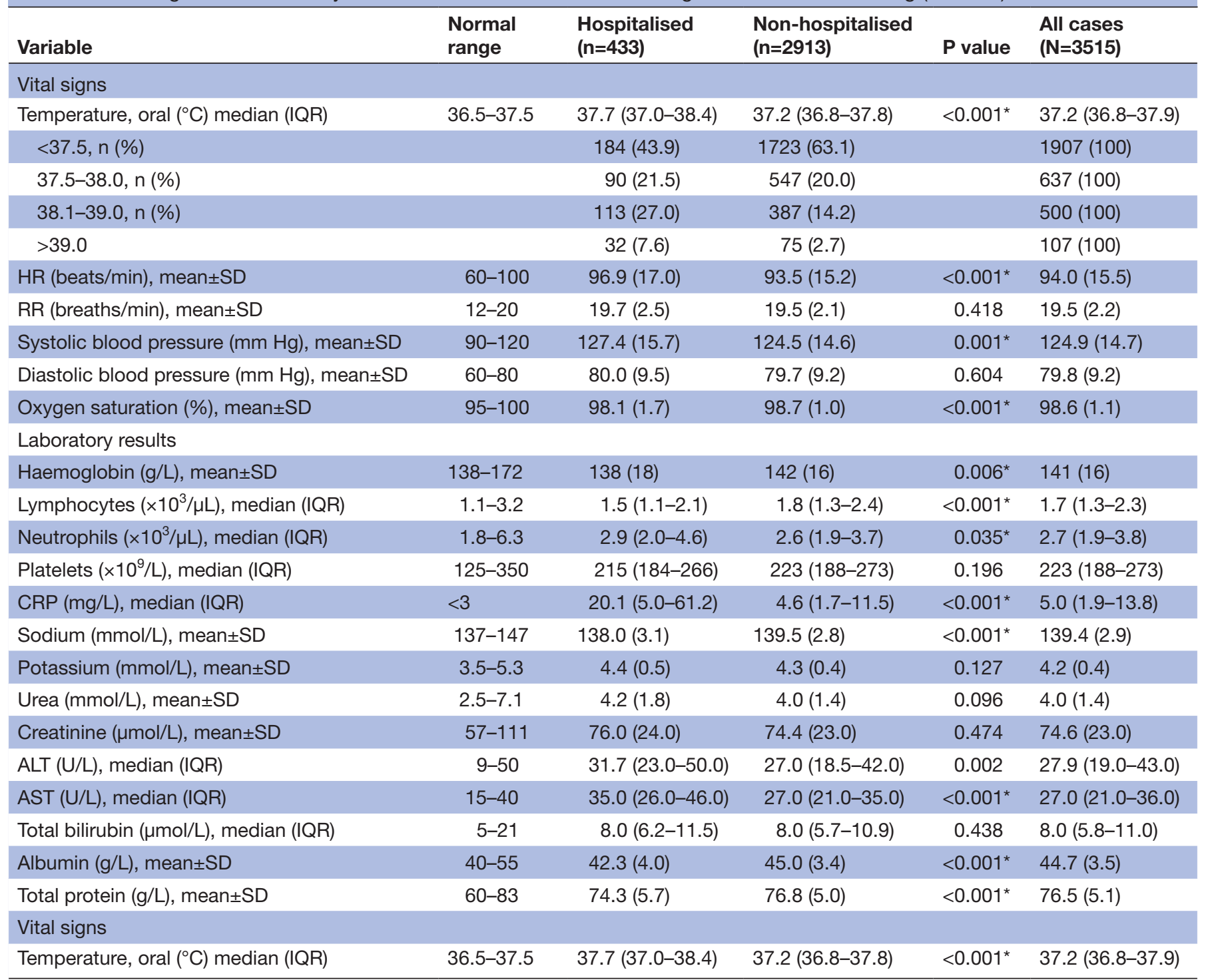

Missing data: temperature ( $n=203), \operatorname{HR}(n=686), R R(n=1800)$, systolic blood pressure $(n=867)$, diastolic blood pressure ( $n=867)$ and oxygen saturation $(n=632)$.

*Indicates statistically significant value.

ALT, alanine aminotransferase; AST, aspartate aminotransferase; CRP, C reactive protein; HR, heart rate; RR, respiratory rate.

to 18 April 2020 found that the patients initially affected were younger (mean age: 34 years), more frequently males $(89 \%)$ with less associated comorbidities $(6.8 \%$ had at least one comorbidity). ${ }^{10}$ This might be indicative of the pattern of pandemic spread in Qatar, where initially the largest peak occurred in the expatriate craft and manual workers, who are usually younger and with fewer comorbidities, before transmission to the local community. ${ }^{10}$

\section{Asymptomatic infections}

Estimating the rate of asymptomatic infection is difficult to perform in most studies, where the definition of asymptomatic cases could be variable, in addition to the fact that most studies do not perform longitudinal follow-up with these initially 'asymptomatic' patients. In PHCC,
Qatar, patients were tested for COVID-19 RT-PCR if they fit the clinical criteria for infection or as contact tracing of confirmed COVID-19 cases, in addition to screening travellers at ports of entry to the country. During the study period, one-third of the cases reported a confirmed contact with an infected person.

The earlier study on COVID-19 in Qatar found that more than $90 \%$ of patients diagnosed between 28 February and 18 April were asymptomatic or had milder symptoms that do not necessitate hospitalisation, while the frequency of asymptomatic cases in the current study was $18 \%$, which is close to the rate reported in a meta-analysis by Byambasuren et al $(16 \%, 95 \%$ CI $12 \%$ to $20 \%),{ }^{19}$ but it was around half of the percentage reported in Kuwait ${ }^{16}$ (around $40 \%$ ) and higher than the percentage reported in KSA $(9 \%){ }^{15}$ 
Table 6 Relationship between the patients' background characteristics and the treatment setting $\left(\chi^{2}\right.$ test) $(\mathrm{N}=3515)$

\begin{tabular}{|c|c|c|c|}
\hline Variable & $\begin{array}{l}\text { Hospital } \\
\text { admission, } \\
\text { n (\%) }\end{array}$ & $\begin{array}{l}\text { Quarantine/ } \\
\text { isolation } \\
\text { facility, n (\%) }\end{array}$ & $P$ value \\
\hline Age (years) & & & $<0.001^{*}$ \\
\hline$\leq 18$ & $21(5.3)$ & 377 (94.7) & \\
\hline $19-49$ & $270(11.3)$ & $2122(88.7)$ & \\
\hline $50-64$ & $108(23.2)$ & 357 (76.8) & \\
\hline$\geq 65$ & $34(37.4)$ & $57(62.6)$ & \\
\hline Gender & & & $0.008^{*}$ \\
\hline Female & $125(10.8)$ & 1031 (89.2) & \\
\hline Male & $308(14.1)$ & $1882(85.9)$ & \\
\hline Nationality & & & 0.225 \\
\hline Arab & $177(12.1)$ & $1281(87.9)$ & \\
\hline Non-Arab & 256 (13.6) & $1632(86.4)$ & \\
\hline Occupation $(n=2675)$ & & & $0.001^{*}$ \\
\hline Unemployed & $60(16.3)$ & 307 (83.7) & \\
\hline Service workers & $81(12.6)$ & $560(87.4)$ & \\
\hline Office staff & $80(14.2)$ & $482(85.8)$ & \\
\hline $\begin{array}{l}\text { Technical } \\
\text { professional }\end{array}$ & $41(14.7)$ & 237 (85.3) & \\
\hline Students & $6(3.3)$ & 177 (96.7) & \\
\hline $\begin{array}{l}\text { Healthcare } \\
\text { professionals }\end{array}$ & $7(8.9)$ & $72(91.1)$ & \\
\hline Housewife & 34 (15.9) & $180(84.1)$ & \\
\hline Others $†$ & $25(10.4)$ & 215 (89.6) & \\
\hline $\begin{array}{l}\text { Number of } \\
\text { comorbidities }\end{array}$ & & & $<0.001^{*}$ \\
\hline Zero & $223(9.2)$ & $2200(90.8)$ & \\
\hline One & $115(19.4)$ & 477 (80.6) & \\
\hline Two or more & $95(28.7)$ & $236(71.3)$ & \\
\hline $\begin{array}{l}\text { Presence of } \\
\text { symptoms }\end{array}$ & & & $<0.001^{*}$ \\
\hline No & 48 (7.9) & $558(92.1)$ & \\
\hline Yes & $385(14.1)$ & 2355 (85.9) & \\
\hline
\end{tabular}

*Statistically significant.

†Includes children and private business.

The clinical characteristics of symptomatic versus asymptomatic confirmed COVID-19 cases were examined in a case series study of 78 patients with confirmed COVID-19 and a history of contact or exposure to the infection. Asymptomatic patients were younger and had a higher proportion of women than symptomatic patients; the median age was 37 years and 56 years, respectively $(\mathrm{p}<0.001)$, and the percentage of women was $66.7 \%$ and $31.1 \%$, respectively $(\mathrm{p}=0.002) .{ }^{20}$ Also, women were more likely to be asymptomatic in comparison to males in a single-centre study in KSA (OR: 0.45, 95\% CI 0.22 to $0.92, \mathrm{p}=0.027) .{ }^{21}$ In the current study, adult patients were more likely to be symptomatic than children and elderly, whereas gender was not correlated with symptoms occurrence.
Table 7 Predictors of hospital admission among patients with COVID-19 (multivariable logistic regression model) $(\mathrm{N}=3515)$

\begin{tabular}{|c|c|c|c|}
\hline Variable & Adjusted OR & $95 \% \mathrm{Cl}$ & $P$ value \\
\hline \multicolumn{4}{|l|}{ Age (years) } \\
\hline$\leq 18$ & Reference & & \\
\hline $19-49$ & 1.750 & 0.902 to 3.394 & 0.098 \\
\hline $50-64$ & 2.614 & 1.281 to 5.332 & $0.008^{*}$ \\
\hline$\geq 65$ & 3.892 & 1.646 to 9.204 & $0.002^{*}$ \\
\hline \multicolumn{4}{|l|}{ Gender } \\
\hline Female & Reference & & \\
\hline Male & 1.303 & 0.940 to 1.807 & 0.112 \\
\hline \multicolumn{4}{|l|}{ Nationality } \\
\hline Arab & Reference & & \\
\hline Non-Arab & 1.223 & 0.947 to 1.581 & 0.124 \\
\hline \multicolumn{4}{|l|}{$\begin{array}{l}\text { Occupation } \\
(n=2675)\end{array}$} \\
\hline Unemployed & Reference & & \\
\hline Service workers & 0.728 & 0.481 to 1.101 & 0.133 \\
\hline Office staff & 0.867 & 0.576 to 1.304 & 0.492 \\
\hline $\begin{array}{l}\text { Technical } \\
\text { professional }\end{array}$ & 0.836 & 0.515 to 1.359 & 0.473 \\
\hline Students & 0.335 & 0.138 to 0.813 & $0.016^{*}$ \\
\hline $\begin{array}{l}\text { Healthcare } \\
\text { professionals }\end{array}$ & 0.549 & 0.235 to 1.286 & 0.157 \\
\hline Housewife & 1.094 & 0.654 to 1.838 & 0.726 \\
\hline Others $†$ & 0.652 & 0.385 to 1.099 & 0.108 \\
\hline \multicolumn{4}{|l|}{$\begin{array}{l}\text { Number of } \\
\text { comorbidities }\end{array}$} \\
\hline Zero & Reference & & \\
\hline One & 2.172 & 1.614 to 2.922 & $<0.001^{*}$ \\
\hline Two or more & 2.628 & 1.802 to 3.832 & $<0.001^{*}$ \\
\hline \multicolumn{4}{|l|}{$\begin{array}{l}\text { Presence of } \\
\text { symptoms }\end{array}$} \\
\hline No & Reference & & \\
\hline Yes & 1.982 & 1.342 to 2.928 & $0.001^{*}$ \\
\hline
\end{tabular}

Dependent variable: hospital admission.

*Statistically significant.

†Includes children and private business.

\section{Spectrum of symptoms}

Fever and cough were the most reported symptoms in the current study (46.7\% and $37.5 \%$, respectively), which were similar to the clinical findings in other studies in the USA, ${ }^{22}$ China ${ }^{15} \mathrm{KSA}^{21}$ and Kuwait. ${ }^{17}$ A review of these studies showed that less than half of patients with COVID-19 had fever at presentation; nevertheless, fever might develop later. In Wuhan, China, $44 \%$ of patients had fever at presentation, but $89 \%$ of patients became febrile during follow-up in hospital. ${ }^{16}$ Other studies have shown a higher frequency of dyspnoea with more severe cases of COVID-19. In China, dyspnoea was documented in $38 \%$ and $54 \%$ of patients with severe disease and with the presence of primary composite end point Intensive Care Unit (ICU) admission, mechanical 
ventilation or death), respectively, in comparison to $15 \%$ and $16 \%$ in patients with the non-severe disease and the absence of primary composite end point, respectively. ${ }^{23}$ Similar findings were also found in the study in Kuwait where the frequency of dyspnoea increased with disease severity with $8 \%, 59 \%$ and $82 \%$ developing shortness of breath in patients with mild-moderate disease, ICU survivors and ICU deaths. ${ }^{17}$ The low percentage of dyspnoea reported in our study might be explained by the fact that patients with milder symptoms tend to present more frequently to primary healthcare.

Although the frequency of ageusia/anosmia was not recorded in the current study, these studies are frequently recorded with active COVID-19 infection. An interesting study by Dini et al on a group of medical residents and physicians in Italy (mean age: $39.4 \pm 14.1,50 \%$ males) found that the positivity rate of RT-PCR correlated with having specific clinical manifestations, including loss of taste/smell (OR: 10.00, 95\% CI 2.80 to $35.69, \mathrm{p}<0.001$ ) and myalgia (OR: $3.20,95 \%$ CI 1.00 to $10.26, p=0.046$ ), with age and loss of taste/smell being the only factors independently associated with positive COVID-19 RT-PCR. ${ }^{24}$

\section{Laboratory abnormalities}

In our study, we found minor differences in the laboratory investigations between hospitalised and non-hospitalised patients. Although patients who were hospitalised were more likely to have higher CRP values and lower lymphocytes count. Similar to the current study findings, a cohort study on 401 patients with mild-to-moderate COVID-19 in five private hospitals in Riyadh, KSA, found that patients with mild and moderate disease severities had high CRP levels $(28.6 \mathrm{mg} / \mathrm{L}$ and $11.1 \mathrm{mg} / \mathrm{L}$, respectively), with mild differences in neutrophil count $\left(4.0 \times 10^{3} / \mu \mathrm{L}\right.$ vs $4.4 \times 10^{3} /$ $\mu \mathrm{L})$, lymphocyte count $\left(2.6 \times 10^{3} / \mu \mathrm{L}\right.$ vs $\left.3.3 \times 10^{3} / \mu \mathrm{L}\right)$, alanine aminotransferase $(35.8 \mathrm{U} / \mathrm{L}$ vs $39.4 \mathrm{U} / \mathrm{L})$ and aspartate aminotransferase (28.4 U/L vs $34.9 \mathrm{U} / \mathrm{L}){ }^{25}$

Clinical deterioration might occur in patients who present initially with mild disease. Therefore, it is important to identify this group of patients for close monitoring and early intervention. Wang et al analysed clinical and laboratory data of 209 adult patients with non-severe COVID-19 who were admitted to a public health centre in Changsha, China. Similar to our study findings, all patients had normal neutrophils and lymphocyte counts, liver enzymes and serum creatinine levels. However, $7.7 \%$ of this cohort of patients progressed to severe cases after admission. Those patients had a lower lymphocyte proportion (median: $23.9 \%$ vs 27.7\%, $\mathrm{p}=0.021$ ) and higher levels of CRP (median: 43.8 vs $12.1 \mathrm{mg} / \mathrm{L}, \mathrm{p}=0.000$ ) and aspartate aminotransferase (median: 29.2 vs $23.2 \mathrm{U} / \mathrm{L}, \mathrm{p}=0.010){ }^{26}$

\section{Predictors of hospitalisation}

The decision for referral and hospital admission in COVID-19 could be challenging to primary healthcare physicians, which is not only dependent on the clinical characteristics of the individual patients but is also variable among different health systems and countries. Early identification indicators on COVID-19 severity were studied by Li et al and included: older age, fever, dyspnoea, level of lymphocytes, CRP, and aspartate aminotransferase and diabetes. ${ }^{27}$ This is consistent with some of the findings in this study, where increasing age and the presence of comorbidities were associated with a higher probability of hospital admission. Moreover, patients who were hospitalised in the current study had higher mean temperature, less absolute lymphocyte count, with higher aspartate aminotransferase and CRP.

\section{Strengths and limitations}

The current study is subject to certain limitations. Some patients had incomplete documentation of the vital signs and exposure history. In addition, recall bias might have affected symptoms reporting. Symptoms like (ageusia/ anosmia) were not among the list of symptoms included in the CDC notification form that was used for data extraction at the time of the study; therefore, we could not include them in the study. Also, information on the COVID-19 variant at the time of the study was not available. Additionally, these data were collected at the time of presentation, which might have changed later with the disease course. Finally, patients with more severe manifestations had probably presented directly to secondary care. Despite that, this study is one of the few studies that were conducted in the primary healthcare setting. Patients were included from all the primary healthcare centres distributed throughout the country who represented different socioeconomic levels and a wide spectrum of disease severity.

\section{Implications of the study findings}

Based on the available evidence, primary care physicians should take into consideration the non-specific nature of COVID-19 when managing patients presenting to primary healthcare. Children and the elderly were less likely to be symptomatic, and most patients had normal vital signs and laboratory investigations at presentation. On the other hand, older age, the presence of comorbidities, having dyspnoea or high CRP were all associated with a higher chance of hospitalisation. However, due to the descriptive nature of this study, further studies are needed to guide screening, stratify the risk of infection and manage patients in the primary healthcare setting.

These data results were collected from the early stages of the pandemic in Qatar; therefore, it would be interesting to re-evaluate the pattern of clinical manifestations for patients presenting to primary care almost 2 years after the pandemic in the presence of different variants and with the wide use of COVID-19 vaccines. It is also essential to conduct longitudinal studies to follow-up the clinical and psychological impact of this pandemic on the population of patients managed in primary care.

\section{CONCLUSION}

The majority of patients with confirmed COVID-19 diagnosed in primary healthcare in Qatar during the study period were symptomatic, but the majority had normal vital signs and blood investigations at presentation. Fever 
and cough were the most common clinical symptoms. Patients who were hospitalised had higher CRP levels and lower lymphocyte count. The most significant predictors of hospitalisation were increasing age, the presence of symptoms and having two or more comorbidities.

\section{Author affiliations}

${ }^{1}$ Department of Family Medicine, Primary Health Care Corporation, Doha, Qatar ${ }^{2}$ Family Medicine Department, Faculty of Medicine, Suez Canal University, Ismailia, Egypt

${ }^{3}$ Department of Medicine, Hamad Medical Corporation, Doha, Qatar

${ }^{4}$ Internal Medicine Department, The University of Jordan, Amman, Jordan

${ }^{5}$ Community Medicine Department of Medical Education, Hamad Medical Corporation, Doha, Qatar

${ }^{6}$ Department of Operations, Primary Health Care Corporation, Doha, Qatar ${ }^{7}$ Department of Community Medicine, Primary Health Care Corporation, Doha, Qatar ${ }^{8}$ Public Health Department, Kasr Alainy Faculty of Medicine, Cairo University, Cairo, Egypt

Acknowledgements The authors acknowledge the efforts made by the staff from the Business and Health Information Department in Primary Health Care Corporation for extracting the research data.

Contributors Conception and design of the study: Ml and AJ. Data acquisition: MI, AJ, MMA, SAA and NAAS. Data analysis: AAD. Data interpretation: MI, AJ, AAD and NAAS. All the authors act as guarantors to the study and contributed to drafting the work or revising it critically, agreed to be accountable for all aspects of the work and approved the final version submitted to BMJ Open.

Funding The authors have not declared a specific grant for this research from any funding agency in the public, commercial or not-for-profit sectors.

Competing interests None declared.

Patient consent for publication Not applicable.

Ethics approval The study was reviewed and approved by the institutional review board at Primary Health Care Corporation in Qatar (reference number: PHCC/ DCR/2020/06/069). The need for consent was waived as data submitted to the research team was anonymous without any patient identifiers (name, date of birth or medical record number). Data protection and confidentiality were maintained throughout the study, and all other research methods involving human participants were carried out per the relevant guidelines and regulations.

Provenance and peer review Not commissioned; externally peer reviewed.

Data availability statement All data relevant to the study are included in the article or uploaded as supplemental information.

Supplemental material This content has been supplied by the author(s). It has not been vetted by BMJ Publishing Group Limited (BMJ) and may not have been peer-reviewed. Any opinions or recommendations discussed are solely those of the author(s) and are not endorsed by BMJ. BMJ disclaims all liability and responsibility arising from any reliance placed on the content. Where the content includes any translated material, BMJ does not warrant the accuracy and reliability of the translations (including but not limited to local regulations, clinical guidelines, terminology, drug names and drug dosages), and is not responsible for any error and/or omissions arising from translation and adaptation or otherwise.

Open access This is an open access article distributed in accordance with the Creative Commons Attribution Non Commercial (CC BY-NC 4.0) license, which permits others to distribute, remix, adapt, build upon this work non-commercially, and license their derivative works on different terms, provided the original work is properly cited, appropriate credit is given, any changes made indicated, and the use is non-commercial. See: http://creativecommons.org/licenses/by-nc/4.0/.

\section{ORCID iDs}

Anwar Joudeh http://orcid.org/0000-0001-8323-1303

Ayman Al-Dahshan http://orcid.org/0000-0001-6132-3223

\section{REFERENCES}

1 Rawaf S, Allen LN, Stigler FL. Global forum on universal health coverage and primary health care. lessons on the COVID-19 pandemic, for and by primary care professionals worldwide. Eur J Gen Pract 2020;26:129-33.
2 Dunlop C, Howe A, Li D, et al. The coronavirus outbreak: the central role of primary care in emergency preparedness and response. BJGP Open 2020;4. doi:10.3399/bjgpopen20X101041. [Epub ahead of print: 0105 2020].

3 World Health Organization. Clinical management of COVID-19: interim guidance, 2020.

4 Mclntosh K, Hirsch MS, Bloom A. Coronavirus disease 2019 (COVID-19). Hirsch MS Bloom 2021.

5 Lipsitch M, Swerdlow DL, Finelli L. Defining the epidemiology of Covid-19-studies needed. N Engl J Med 2020;382:1194-6.

6 Epidemiology Working Group for NCIP Epidemic Response, Chinese Center for Disease Control and Prevention. TThe epidemiological characteristics of an outbreak of 2019 novel coronavirus diseases (COVID-19) in China]. Zhonghua Liu Xing Bing Xue Za Zhi 2020;41:145-51.

7 Primary Health Care Corporation. PHCC corporate annual report 2019. Available: https://www.phcc.qa [Accessed 25 May 2021].

8 Ministry of Public Health in Qatar [Internet]. Coronavirus disease 2019 (COVID-19), 2021. Available: https://covid19.moph.gov.qa/EN/ Pages/default.aspx [Accessed 1 Oct 2021].

9 National Institute of Health [Internet]. Clinical spectrum of SARS-CoV-2 infection 2020, 2021. Available: https://www.covid19treatmentguidelines. nih.gov/overview/clinical-spectrum [Accessed 11 Feb 2021].

10 Al Kuwari HM, Abdul Rahim HF, Abu-Raddad LJ, et al. Epidemiological investigation of the first 5685 cases of SARSCoV-2 infection in Qatar, 28 February-18 April 2020. BMJ Open 2020;10:e040428.

11 Khan M, Khan H, Khan S, et al. Epidemiological and clinical characteristics of coronavirus disease (COVID-19) cases at a screening clinic during the early outbreak period: a single-centre study. J Med Microbiol 2020;69:1114-23.

12 CDC [Internet]. Contact tracing for COVID-19, 2020. Available: https://www.cdc.gov/coronavirus/2019-ncov/php/contact-tracing/ contact-tracing-plan/contact-tracing.html

13 Fisher T. TaqPath COVID-19 Combo kit [internet], 2020. Available: https:// assets. thermofisher. com/ TFS- Assets/ LSG/ manuals/ MAN0019372_TaqPathCOVID-19_Kit_Australia_ NZ_ IFU. Pdf [Accessed 18 Jan 2021].

14 Roche. Cobas $\AA^{2}$ SARS-CoV-2 test [internet], 2020. Available: https:// www.diagnostics.roche.com/us/en/products/params/cobas-sarscov-2- test.html [Accessed 18 Jan 2021].

15 Alsofayan YM, Althunayyan SM, Khan AA, et al. Clinical characteristics of COVID-19 in Saudi Arabia: a national retrospective study. J Infect Public Health 2020;13:920-5.

16 Guan W-J, Ni Z-Y, Hu Y, et al. Clinical characteristics of coronavirus disease 2019 in China. N Engl J Med 2020;382:1708-20.

17 Alshukry A, Ali H, Ali Y, et al. Clinical characteristics of coronavirus disease 2019 (COVID-19) patients in Kuwait. PLoS One 2020;15:e0242768.

18 World population review [Internet], 2020. Available: https://worldpopulat ionreview.com/countries/qatar-population [Accessed 18 Dec 2020].

19 Byambasuren O, Cardona M, Bell K. Estimating the extent of asymptomatic COVID-19 and its potential for community transmission: systematic review and meta-analysis. medRxiv 2020.

20 Yang R, Gui X, Xiong Y. Comparison of clinical characteristics of patients with asymptomatic vs symptomatic coronavirus disease 2019 in Wuhan, China. JAMA Netw Open 2020;3:e2010182.

21 Shabrawishi M, Al-Gethamy MM, Naser AY, et al. Clinical, radiological and therapeutic characteristics of patients with COVID-19 in Saudi Arabia. PLoS One 2020;15:e0237130.

22 Stokes EK, Zambrano LD, Anderson KN, et al. Coronavirus Disease 2019 Case Surveillance - United States, January 22-May 30, 2020. MMWR Morb Mortal Wkly Rep 2020;69:759-65.

23 Jiang F, Deng L, Zhang L, et al. Review of the clinical characteristics of coronavirus disease 2019 (COVID-19). J Gen Intern Med 2020;4:1-5.

24 Dini G, Montecucco A, Rahmani A, et al. Clinical and epidemiological characteristics of COVID-19 during the early phase of the SARSCoV-2 pandemic: a cross-sectional study among medical school physicians and residents employed in a regional reference teaching hospital in northern Italy. Int J Occup Med Environ Health 2021;34:189-201.

25 Al Mutair A, Alhumaid S, Alhuqbani WN, et al. Clinical, epidemiological, and laboratory characteristics of mild-tomoderate COVID-19 patients in Saudi Arabia: an observational cohort study. Eur J Med Res 2020;25:1-8.10.1186/s40001-02000462-x

26 Wang G, Wu C, Zhang Q, et al. C-reactive protein level may predict the risk of COVID-19 aggravation. Open Forum Infect Dis 2020;7:ofaa153.

27 Li L, Sun W, Han M, et al. A study on the predictors of disease severity of COVID-19. Med Sci Monit 2020;26:e927167-1. 